\title{
OUTCOMES AND LESSONS FroM DEPLOYING DIGITAL Notebooks ACross A MulTi-SECTION ENGINEERING DESIGN Course
}

\author{
John K. Dickinson, Ph.D. \\ Faculty of Engineering, Western University \\ jdickin5@uwo.ca
}

\begin{abstract}
The instructor team of large cohort, team- and project-based, first-year engineering design course were faced with a number of common and persistent challenges; effective modelling and scaffolding of the design process; realizing consistent content delivery, marking, and feedback across multiple sections; keeping student teams on track; capturing individual marks related to teamwork; and establishing good design notebook keeping practices. As part of continuing course updates, distributed digital notebooks including worksheets were progressively introduced to support project and team learning activities and individual assessment and feedback. This paper examines the outcomes and lessons learned from the increasingly expanded role these notebooks have taken and their impacts on both instructors and students. In practice, the digital project notebooks have shown themselves to be surprisingly versatile as a platform to 1) deliver course content, 2) enable regular evaluation of individual student participation, contribution, and/or understanding, 3) record and assess team-level progress on the project, and 4) capture and monitor the evolution of team plans and ongoing activities. However, there are some observed costs to the implementation approach taken so far, including potential loss of flexibility, inhibiting teams from taking initiative or learning to manage their own time and effort.
\end{abstract}

Keywords: engineering education, digital notebook, notebook application, multi-section course, cross-section consistency, feedback, evaluation, team-based learning (TBL), project-based learning (PBL), foundational course, design course

\section{INTRODUCTION}

Large cohorts are a reality for many engineering programs across Canada. According to Engineers Canada's 2008 "Enrolment and Degrees Awarded Report" [1] there were 57,225 undergraduate students enrolled in engineering. By 2017 [2], the number of undergraduate students had increased to 82,473 , an almost $45 \%$ increase, at least partially reflected in many yearly cohorts. A quick review of Engineer's Canada 2017 data shows that 10 universities across Canada had cohorts of greater than 300 students in common first-year programs, and at least another 23 discipline specific programs had graduating classes of 200 students or more.

At Western University, a common first-year curriculum results in almost 600 students simultaneously enrolled in ES1050: Foundations of Engineering Practice. ES1050 focusses on the engineering design process, teamwork and communication skills and is built around 2 or 3 larger projects undertaken by student teams over course of the academic year. Over the last few years, the course has steadily evolved but the cohort size continues to require a multi-section approach. Students are split into four 2-hour "Workshop" sections with $\sim 150$ students each and 12 2hour "Studio" sections with $\sim 50$ students each. Workshops focus on building individual skills including creating pitches, project management, spreadsheets, sketching and basic solid modelling through a mostly flipped teaching approach [3], with online lesson material followed by faceto-face interactive practice or hands-on sessions. Studios host project and team-based learning (PBL [4] \& TBL [5]) with teams of 3-5 (2017-18) and 4-6 (2018-19 and on) working on 2-3 design projects. Student teams are encouraged to find their times outside scheduled studios to meet and work on projects as needed.

In 2017-18 and 2018-19 the schedule also included a 1hour entire cohort lecture that was used to deliver theory and logistic elements to the students. However, in 2019-20 this element was all but discontinued, eliminating the last portion of the course presented to all students by the same instructor. One driver of this change was student frustration and dropping attendance caused by inconvenient lecture 
locations and times that were in turn caused by universitywide competition for a limited number of campus venues capable of hosting the entire cohort simultaneously. Instead, original lecture content is now integrated into the digital design notebooks, in flipped workshop content or in other online resources (more on this in Section 3) making it immediately available during related course activities.

This multi-section, multi-instructor course delivery presents significant challenges in achieving consistency in content and presentation delivery, grading and feedback, keeping teams on track, capturing individual marks related to teamwork, and establishing good design notebook keeping practices. This paper examines how distributing and assessing weekly worksheets in a digital notebook using Microsoft OneNote Class notebooks has evolved into one of the major tools for pursuing these goals.

It should be noted that other complementary tools and practices that impact course delivery and consistency have also been progressively introduced into the course in recent years but are not the focus of this publication. Two tools worth mentioning are Piazza (https://piazza.com) and Gradescope (https://www.gradescope.com). Piazza is used as a course-wide, incentivised and monitored, student and instructor discussion forum as well as a mechanism to make course announcements. Gradescope is used to establish common assignment marking rubrics and feedback across sections. Examples of practices used to improve course consistency include overlap in Workshop instructors (1 instructor delivering 2 of 4 Workshop sections reaching half the class), common individual and team assignments, mid-year and final exams (2017-18 and 2018-19), a common course culminating design showcase and regular announcements outlining course expectations for the coming week released Friday or Saturday.

The next section reviews some of the literature findings on the use of digital notebooks in course instruction. Following this is an account of the progressive deployment of digital notebooks in ES1050 over the last three years and the resulting student and instructor experiences. The paper closes with a review of Outcomes and Lessons Learned and some areas for future development or investigation.

\section{LITERATURE}

Digital notebooks have been used in classrooms for many years and have recently flourished as both web technology and laptops have increased in availability and capability. There is a small but growing body of published research investigating the use of digital notebooks for: instruction and practice of the design process, facilitating team collaboration (group effort including reviewing each others' contributions, expanding on ideas and overcoming obstructions), and supporting assessment and feedback.

\subsection{Supporting the Design Process}

A 2007 paper [6] reviewed the application of early tablet PCs by a small subset of 160 students in a capstone design project. Their approach of requiring weekly "memos" on team progress and reviewing notes, calculations and decision entries is very similar to current practices in ES1050. The paper noted that the teams with the tablets made better records of meeting discussions, decisions and design changes, captured more engineering analysis as the design evolved later in the term, and were better at recording and sharing meeting minutes and communications. They also noted that the greatest benefits to teams were observed in the early phases of design when investigating the problem, generating concepts and making decisions on approaches.

Two studies [7], [8] on using digital notebooks to support lab work yielded similar lessons to [6], including improved problem exploration and record keeping, despite using different implementation platforms. Instructors liked having student logbooks available to consult before responding to student questions and many students preferred digital over paper versions. Importantly, the later study ([8]) emphasised student participation in deciding what a lab notebook should look like as part of establishing student buy-in. One drawback observed was that some students had trouble distinguishing between expectations for writing styles in informal logbooks and formal reports.

On a side note, in [9] structured, i.e. not blank, paper based design notebooks were used to scaffold the Design Thinking process in an approach unwittingly duplicated digitally in ES1050. The publication notes that one student felt the structured notebooks were good for supporting the process and keeping him on track instead of completing/backfilling the notebook at the end.

Collectively, these papers suggest that structured guidance and regular feedback enabled by digital notebooks can help teams be more focused and engaged and learn more in earlier project phases. This benefit was observed in the ES1050 application context.

\subsection{Supporting Team Collaboration}

One early source of inspiration for supporting student collaboration came from Wikis, which are structured and collaboratively edited knowledge base websites. A 2009 survey of wikis as a design support tool [10] found the natural collaborative nature, ability to contribute a variety of types of content and ease of organisation made Wikis valuable for facilitating collaboration. However, the survey also noted that the technology of the time was limited in its support for graphics and metadata capture, important features for engineering applications. This is likely to be a lesser concern with today's technology.

More recently, a study [11] investigated using Microsoft SharePoint and OneNote in a second year course to provide a team notebook, document library and discussion forum. 
Unfortunately, although students used the digital tools there was little evidence of resulting collaboration. Instead students continued to rely on dividing up tasks. The paper posed the question; can teams be incentivised to collaborate and not just divide and conquer? A subsequent publication [12] found some success using Microsoft Teams as a platform for collaborative team interaction with a class of $3^{\text {rd }}$ year engineers, but the amount of instruction given on collaboration was unclear and the question above remains open to investigation.

\subsection{Supporting Assessment / Feedback}

Digital notebooks also offer benefits for course assessment activities. To start, technology often provides the opportunity for rapid assessment, feedback and permitting revised student submissions as observed in both [7], [8], with digital logbooks used by students in lab settings. Unfortunately, the same papers also observed that cheating/copying became harder to detect.

That said, in one study on a course with a number of similarities in content to ES1050 [13], the notebook grades were demonstrated to correlate with the results of peer evaluations of team member participation. Possibly contributing to this correlation was the emphasis placed on instructing the students on how to write effective design notebooks and engage in reflective thinking in engineering design.

Not surprisingly, other papers (e.g. [14]) have shown design notebooks are a valuable tool in evaluating student knowledge application, and thus their practical understanding, of the design process in a PBL context. Collective findings suggest notebooks, if properly maintained, capture the process steps students execute and the order they are taken in, along with all related analyses and resulting design decisions. The key issue is how to encourage proper notebook completion by students.

\section{DIGITAL NOTEBOOK USE IN ES1050}

\subsection{ES1050 Project Structure}

Although the general course section structure remains constant, the project assignments, schedule and intent have varied somewhat over the last three academic years.

The first project (6 weeks duration fall $2017 \& 2019,8$ weeks 2018) is intended to be an introductory challenge to build something fun but functional in a team context. Considerable emphasis is spent on teams experiencing the ideation through functional prototyping stages of design to make devices that sort, flip, convey or position objects. Teams reflect on their team experience at the end of the project before developing a Team Charter for project 2 .

The second project ( 6 weeks, in 2018 this was a mostly individual effort over 4 weeks instead) has students learning about identifying, researching and understanding need, creating problem definitions, evaluating existing potential solutions and presenting their conclusions. This typically looks at larger scale problems like campus waste reduction, STEM teaching aids or global plastic pollution.

The third project is summative, encompassing the entire design cycle, and closes with a public design showcase with working prototypes (12 weeks) with projects set within broad thematic areas like wheelchair users, educational aids, and community living.

\subsection{Technology and Methodology of Deployment}

Although there were numerous collaboration platforms available in 2017, including Google's suite of web-based office applications and Evernote (https://evernote.com/), none could be identified as having the same feature set tailored for ES1050 instructional setting as Microsoft OneNote Class (e.g. separate instructor and student spaces and capabilities, simple page distribution, support for grading workflows, Canadian storage of data, inclusion in existing academic site licence).

The course coordinator made 12 OneNote class notebooks (1 for each studio section) and invited the students into their own private notebook sections through their university email accounts. Students can view and edit their notebooks online through web browser interfaces, use OneNote apps on all major mobile platforms, or use fullfledged laptop/computer OneNote applications available on both Apple and Microsoft platforms.

From the instructor and TA perspective, each studio appears as one large notebook (Figure 1) with all students visible in individual sections. Setup configuration options also allow including a common Content Library section editable only by the instructors but visible to all students in the notebook and a Collaboration Space that everyone can see and edit (to enable content sharing between students/teams). Teams are even able to make private subsections (password protected) under the Collaboration Space section to use when collaborating amongst themselves. Note, instructors are unable to access these sections without the password.

Each class notebook allows the creator to add instructors and students using separate lists of emails and the system automatically sends an email with an invite link to $\log$ into the notebook the first time. Configuration can include including a Collaboration Space, or Content Library and even predefined Student Notebook sections, in our case Project 1, 2, and 3 Trackers in for the 2019-20 course.

Microsoft Class Notebook is under constant development, but some basic functionality has remained consistent. A desktop application add-in or the online OneNote pages allow simple distribution of instructor created pages to all students in a Class Notebook, or across all students in multiple Class Notebooks. Students and instructors can also be added or removed from a notebook as needed. The common structure and grading-centric navigation tools makes it easy to check the contents of the 
same page for all students and leave freeform or typed feedback for students directly on their pages. History information for pages is also available so instructors can see when students made each entry (generally on a single day granularity).

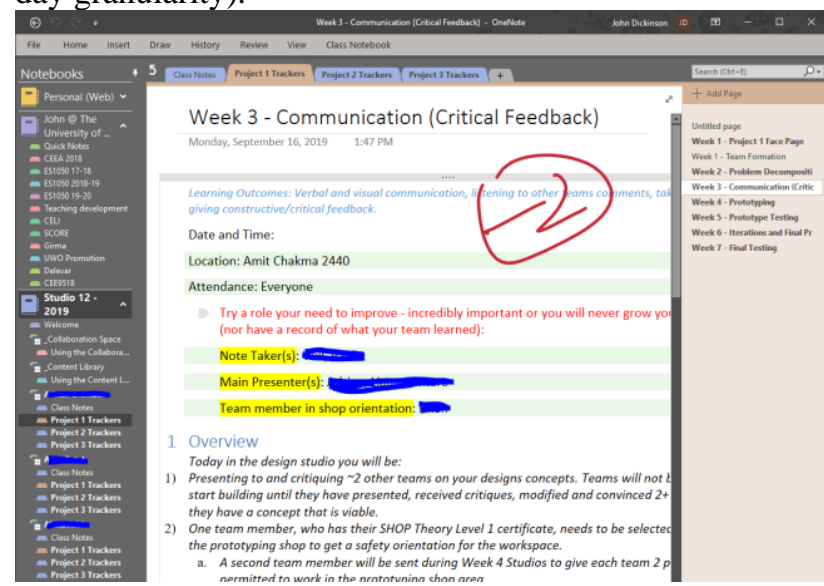

Figure 1: Sample Digital Notebook Instructor View 2019-20 using Microsoft OneNote Desktop. Each blue cross-out on the left is the root of a different student's notebook section. Different pages for each section are accessed through the bar on the right.

\subsection{Notebook Deployment 2017-18}

The first year the Digital Notebooks were introduced into the ES1050 course, they were deployed as an optional digital replacement for the traditional bound paper design notebooks. At the beginning of the academic year, all students, whether using digital or paper notebooks, were given the same overview on the importance of using design notebooks and instructions for required sections (Face / Title page, Table of Contents, 30 pages of meeting notes, and personal design notes) and format. Guidelines included working in ink unless sketching, inserted pages needed to be attached using glue, staples, or tape, and that pages needed to be numbered. Pages started out as blank in both formats but a sample reusable template for the face page was made available for the Digital Notebook.

The notebooks were formally graded twice a year, at the end of each term and were worth 5\% of the total course mark $(2.5 \% /$ term). In theory TAs would check and provide brief verbal advice for each week's entry during the design studio time, although execution of this was very spotty and varied studio to studio and week to week. The biannual marking presented logistic challenges for submission, assignment lockers having slots too small for larger bound books or becoming full due to book bulk. Boxes of books were heavy and hard to store or move. Many students failed to retrieve books after the winter term and instructors were required to keep them for 1 year and then dispose of them in a way that preserved privacy.

Many students didn't appreciate or keep good notebooks and invested significant time near submission times back filling their entries. At $2.5 \%$ each they weren't treated as important by students nor TAs and grading itself was inconsistent. Over $11 \%$ failed to submit notebooks for the Fall and $12.5 \%$ for the Winter Term. Average mark variations between studio sections was very high with standard deviations of $25.9 \%$ for the fall term and $30.2 \%$ for the winter term (see Figure 2).

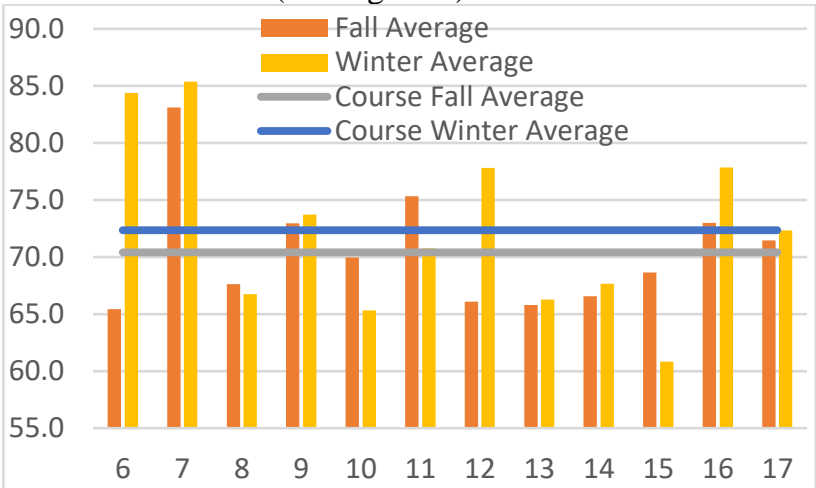

Figure 2: Average studio section Project Tracker grades for the 2017-18 fall and winter terms.

In the initial year students were given the opportunity to pick their preferred notebook platform for the duration of each of the 3 course projects and few students used the digital notebooks throughout the entire course. However, of those who did, they often kept copious and high-quality notes and clearly demonstrated that digital notebooks were feasible (see Figure 3). The instructional team recognised that the digital notebooks required minimal logistics for collecting and marking and could be monitored more effectively in real time (without requiring viewing 50 notebooks at the end of a studio session).

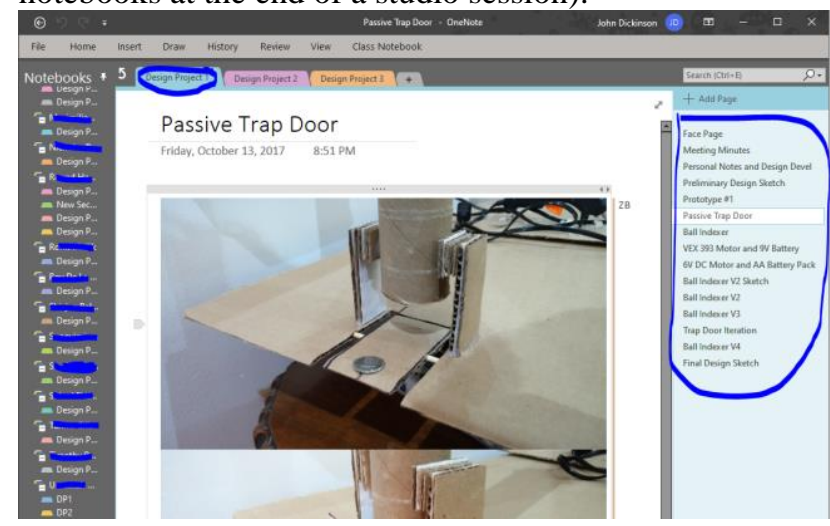

Figure 3: Snapshot of one student's design notebook from $2017-$ 18 showing the regular collection of project information including pictures of prototypes (Project 1 section).

The only course feedback comment by a student (regarding notebooks) from 2017-18 indicated strong interest in using digital notebooks and frustration with the current practices: (verbatim)

"something needs to be done about the design notebooks. everyone does them last minute. maybe actually checking them would help, or having them be due halfway through a semester for a checkpoint. 
Something to encourage people to do them at the time. Also i would definitely push the onenote notebooks harder, they're way more convenient but nobody seems to know about them."

\subsection{Notebook Deployment 2018-19}

During a course redevelopment for the 2018-19 year the instructors decided to try several new initiatives based on replacing all paper notebooks with a digital notebook containing weekly worksheets (called Project Trackers). Several goals were tied to this initiative:

1. To systematically model the design process through activity and tasks related to completing the project in worksheets.

2. To establish more consistent instructional and activity content in each studio section and provide links to or reminders of relevant instructional material provided elsewhere in the course.

3. To help teams keep on track in their projects.

4. To capture individual marks related to project teamwork.

5. To promote more regular recording of design notes and minutes and thus the importance of keeping a notebook.

6. To have a common resource when mediating disagreements regarding project mark distributions.

In the 2018-19 academic year, each worksheet was worth 10 marks in total but the sections the students were required to complete were specific to the activities of the week. That said, action item lists and Gantt charts were almost always part of the worksheets. Student entries were marked weekly and the marks recorded in a shared coursewide spreadsheet. Notebook, and thus Project Tracker, grades were worth $10 \%$ of a student's final course mark (double the previous year's weighting).

During the winter term, when the teams were working on a larger summative project, the trackers were used less to deliver instructional material and instead became more generic or free flowing to give students an opportunity to use the space as their project process and progress dictated. The sheets typically required meeting minutes, action items and updated Gantt charts with occasional larger specified entries that would be reused in the team's final project report.

Initially, there were some notable technology issues in distributing pages to student notebooks or accessing them online when many students were working simultaneously. As well, syncing issues could lead to student confusion and multiple entries. However, the frequency of these issues dropped significantly over the year. In the 2019-20 year these issues have been virtually nonexistent.

The author received student feedback twice from 4 sections personally taught during this academic year and only 5 comments mentioned notebooks or project trackers (1 positive and 4 negative): (verbatim)
- "The project trackers where useless and a waste of time, they did not help our group during our project at all."

- "some rules in his course weren't really useful; like mandatory attendence, some workshops, SOTA report and project trackers."

- "Project trackers and weekly quizzes are good in keeping the students on track"

- "Project trackers are painful and pointless. Studios should be dedicated to group work on projects."

- "One possible approach to this course is to continue 2 hour studios, however take the focus off the project trackers which don't promote group discussion."

The project tracker marks told a more interesting story. First, almost all the students were completing the Trackers regularly (only $3 \%$ had marks of $40 \%$ or less compared to $\sim 12 \%$ in the previous year). Second, although the variation between studio sections averages remains higher than desired at $+/-10 \%$ (Figure 4 ) from the course average standard deviation of individual marks was reduced to $17.4 \%$ compared to $25-30 \%$ in the previous year.

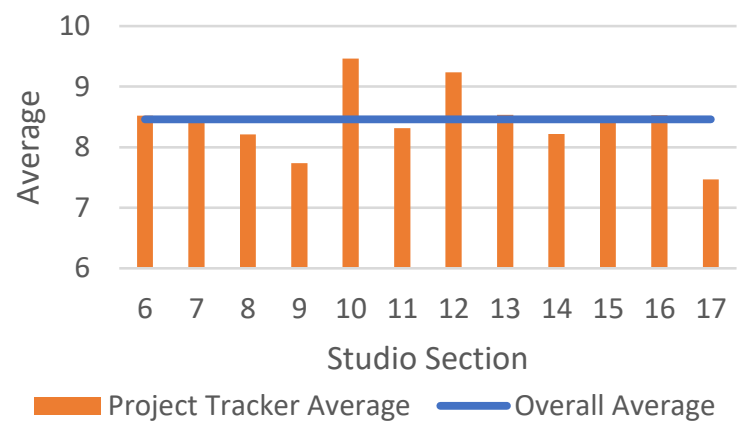

Figure 4: 2018-19 Final Project Tracker average grade spread across studio sections.

\subsection{Notebook Deployment 2019-20}

In general, the 2018-19 year was sufficiently successful that the instructor team limited changes to adjust the marking schemes applied and updating worksheets. Even more theory or background content was embedded to deliver instructional material and replace the discontinued course-wide lecture. Studio sessions were run by instructor teams (Professors and TAs) based on a weekly instructor communication and the tracker content.

Marking remains weekly but the marks earned per worksheet varied dependant on the project tracker entry requirements and counted towards different aspects of the course grade as opposed to being separately tracked. This was due to efforts made to use the tracker entries to further document individual contributions during the first two projects of the course and provide more freedom / flexibility in the winter term. 
- Fall: Tracker entry marks make up a portion of an individual's project marks - Project 1: $40 \%$, Project 2: $23 \%$.

- Winter: 4 individual marks per week were recorded as part of an engagement mark for the course. Weekly marks came from assessing student tracker entries of team action items, updated Gantt chart, and personal reflections on how their individual project tasks contribute to advancing the current design process stage. Three special tracker entries were also used to capture another $9 \%$ component of an individual's marks for Project 3.

As before, an online shared spreadsheet was used to record weekly tracker marks. Approximately every 2 months they were summarised and placed in the student course gradebooks as well as indicated as annotations by markers in student notebooks themselves.

Unfortunately, standard feedback questionnaires for the end of the winter 2020 academic term were cancelled due to the pandemic but an anonymous closing poll was posted in the course forum once the course had closed. It received limited response rates but asked students to vote for the course elements they thought should be kept or introduced into the course. Of the 51 responses made, 57\% supported the use of OneNote based Project Trackers as a mechanism for partially assessing individual contribution to projects as done in the fall term, and $47 \%$ supported the use of trackers as an assessment of their broader contribution to the course as tried in the winter term. Furthermore, 37\% of students indicated support for switching to Microsoft Teams (which can include a OneNote Class component) with follow-up comments indicating that students who were familiar with Teams liked it as a project collaboration platform.

The few student comments on the poll were polarised regarding the trackers.

- $\quad$ reduced] " ... a good chunk of the exercises in the project trackers were a waste of time. We had to spend too much time writing something in the tracker just for the sake of not leaving it blank. ... I adopted this attitude towards the trackers because it seemed it me that they were marked with the same lousy attitude. I got the impression that they were just skimmed over and the marks were given for the amount of content rather than the quality of it. ... Having said all that, I understand the value of self reflection and the idea that was behind the trackers. In my opinion it doesn't need to be removed completely, but rather improved somehow."

- "The trackers were AMAZING. they force the teams to stay and discuss as opposed to very quickly leaving without much consideration. Forcing us to work together to complete a task bonded us and helped us share ideas."

In review, it seems the variable marking scheme for tracker entries to match expected individual effort was overly complex (varying from project to project, week to week) and was not sufficiently clearly explained. As well, some students in the winter term were found to be only paying attention to and completing the parts of the tracker where marks were explicitly assigned, nullifying some of the usefulness of the trackers as project guides.

As noted earlier, distribution issues of pages were all but gone or were generally evident immediately. Syncing and access issues for students were also very rare and usually traceable to problems with the student's technology or account.

\section{OUTCOMES AND LESSONS}

\subsection{Instructor and TA Feedback}

The 2019-20 instructor and TA team were polled for their opinions on the use of the project trackers in the course. Excerpts from their feedback highlight some of the strengths and weaknesses of the approach.

Pros:

- "I am in full support of the project trackers. I think that they provide a step by step guide to develop their design tools and ensure that students are on track. Even yesterday when I was out of the room during the evaluations, I was comforted that students knew what to work on and were on track. The first year in the course I felt like I had to walk around and keep everyone going....moving forward. Now I find students are always working on something and I can then focus on providing feedback/direction of their design. It forces the students to plan ahead as well and all to take notes. These students are very digital, so the online project tracker is fine for them. I am in FULL support!"

- "Helps to keep students on track when working on projects by clearly indicating the work that is expected each week. Avoids procrastination and straggling."

- "Much easier to evaluate and provide timely feedback when compared with hardcopy design books used before, although from my experience most TAs are not providing much in the way of feedback."

- "Provides a cohesive look and format for each student and TA for marking purposes"

- "Aids in standardizing studio delivery"

- "Provides structure for studio work periods"

- "Aggregates important information in one location"

- "Quite beneficial to some (generally lowerachieving) groups"

\section{Cons:}

- "Tends to limit work done each week - students feel that once they have filled in the blanks, they are done for the week" 
- "Reduces options for flexibility within the studio teams not encouraged to progress more rapidly than the trackers"

- "Students not encouraged to develop their own time-management skills by working towards milestones."

- "Tracker entries tend to be rather superficial potentially limiting deeper thinking later"

- "Limited flexibility for students to record and share design work"

- "Quite limiting for other (generally higherachieving) groups"

- "Reduces the weight (as a percentage of grade) of formal technical writing ... which is a skill that I find most engineering students need to work on."

- "marking was difficult and even with a guide it was difficult to keep things similar across studios and TAs"

- "Many students just copied from their teammates and this was difficult to monitor"

\subsection{Conclusions and Outcomes}

All members of the teaching team who gave feedback found multiple positive benefits for deploying Digital Notebooks in the course. In particular, they noted how cross-section consistency for content, grading and progress was supported by the notebooks with less overhead (meetings, communications ...) for the instructor team. This was not something found by the author in the existing literature. Where cons were identified, they are not perceived to be deal breakers and the author remains hopeful that they can be mitigated or better addressed in future applications of the digital notebooks.

In short, the digital notebooks have changed the face of ES1050. They have proven useful in (with references to publications with similar findings in brackets):

- Distributing consistent course content and modelling the design process, and simplifying cross-section instructor coordination,

- Improving consistency in mark aggregation, and cross-section student experience,

- Keeping teams more on track ([9]) and engaged,

- Providing an opportunity for more regular feedback to students ([13]) especially in early project phases,

- Allowing instructors to keep a closer eye on student's engagement / participation and progress and potentially intervene earlier when students or teams get into difficulty,

- Familiarising students with a very flexible and useful note taking tool common in industry ([11]).

That said, they are not without their weaknesses (with references to publications with similar findings in brackets):
- $\quad$ Students often still consider notebooks make-work and buy-in varies with non-graded elements at risk of being skipped,

- Simplifies sharing of information within teams for collaboration but also enables students to copy each other's submission ([7], [8]),

- Can artificially limit team progress and their ability to learn to manage their own project efforts.

- Consistency in notebook assessment and feedback remains important and when lacking can notably decrease student buy-in and thus learning benefits.

- Logistical challenges continue to exist in terms of providing regular grading summaries since this is not a current built-in feature of the notebooks.

\subsection{Lessons Learned}

When this initiative started in 2017, it was not clear the technology was ready, and some workarounds were required. That seems to be no longer the case and the main lesson related to using Microsoft OneNote Class technology (and possibly others) would be to use institution level accounts separate from the instructor's personal account to set up the notebooks. This avoids rapidly consuming instructor allocated drive space and simplifies the "digital" disposal or archiving of student submissions at the completion of the course. Also, be ready to provide some initial support or instructions getting students into their OneNote "course" notebooks.

On the pedagogical side, there are some common lessons worth reiterating regarding deployment of the digital notebooks.

1. Plan sessions to educate students on the importance, expected use and assessment of their notebooks as part of their learning experience (e.g. involve them in creating the worksheet template).

2. Provide regular practical demonstrations of their value to avoid students considering them makework (e.g. include worksheet elements that are reused by students graded submissions like reports or in the subsequent week's activities).

3. Initially use worksheets to scaffold the desired capabilities and knowledge and later allow students to demonstrate these more independently.

4. Distributing all the worksheets for a project at the start may lead to a better instructional flow and more flexible rates of team progress.

5. Provide clear marking schemes (for both instructors and students) that are linked to desired capabilities or behaviours AND the project. Note: Elements without marks are at risk of being ignored.

6. Regular feedback needs to go beyond simple marks.

7. Review notebooks regularly to identify students or teams potentially in difficulty.

8. Keep worksheets concise but useful as a guide by dynamically linking to more detailed supporting 
material hosted elsewhere. A potential drawback to this is that students may fail to make copies of linked content before course notebooks are closed at the completion of the academic year.

\section{FUTURE RESEARCH}

For the upcoming year, the author intends to revisit and improve how the worksheet elements link (model, capture or support) the project process being taught to the students. Consideration will be necessary to ensure adequate, not smothering, scaffolding is provided in the first term, more flexibility is available in later projects, and feedback encourages students to adopt good note taking practices without making marking laborious. Hopefully properly designed worksheets can foster team initiative taking and learning to manage their own project work while reducing remaining inconsistencies in grading and feedback.

Further future developments could also include providing a more formalised, common (living, instructor maintained) course manual in a notebook section accessible to all course participants instead of pushing everything to individual student pages.

Alternately, continuing development in collaboration suites and services like Microsoft Teams, Slack, G Suite ... which integrate support for discussion forums, file sharing, task planning, etc. means there are new options. Microsoft Teams actually includes OneNote class capabilities which may simplify its use for the current ES1050 digital notebook workflows.

\section{Acknowledgements}

The author would like to acknowledge the ES1050 course redesign team; Dr. Lauren Briens, Dr. Mike Bartlett, Sara Holland M. Eng. Sci., and Dr. Beth Hundey who supported the implementation of digital notebooks. Thanks also to the ES1050 instructor team for the 2017-18, 201819 and 2019-20 course years, unfortunately too many to name individually here. The author also owes thanks to the people in the Centre for Teaching and Learning at Western University for assistance in tackling many pedagogical quandaries and practical teaching challenges. Lastly, the author would like to thank Prof. Emeritus Ralph Buchal for convincing him that Microsoft OneNote Class technology was ready for use on a large scale and encouraged deploying digital class notebooks across ES1050.

\section{References}

[1] "Canadian Engineers for Tomorrow: Trends in Engineering Enrolment and Degrees Awarded 20082012," Engineers Canada, Sep. 2013. [Online]. Available: https://engineerscanada.ca/sites/default/files/enrolment_r eport_2012_eng.pdf.
[2] V. Rossi, "Canadian Engineers for Tomorrow: Trends in Engineering Enrolment and Degrees Awarded 20132017," Engineers Canada, 2018. [Online]. Available: https://engineerscanada.ca/sites/default/files/enrolment_r eport_2012_eng.pdf.

[3] Facebook et al., "The Flipped Classroom Explained Flipped Learning in Adelaide." https://www.adelaide.edu.au/flipped-classroom/about/ (accessed May 05, 2020).

[4] "What is PBL," PBLWorks. https://www.pblworks.org/what-is-pbl (accessed May 05, 2020).

[5] J. Sibley and P. Ostafichuk, Getting Started With TeamBased Learning. Sterling, Virginia: Stylus Publishing, LLC, 2014.

[6] B. Surgenor and K. Firth, "Application of tablet computers in a capstone design course," in 2007 Proceedings of the ASME International Design Engineering Technical Conferences and Computers and Information in Engineering Conference, DETC2007, 2008, vol. 4, pp. 533-538, doi: 10.1115/DETC2007-34289.

[7] S. S. Holland, J. L. Bonniwell, and J. D. Carl, "A review of electronic engineering logbooks throughout the electrical engineering curriculum," in ASEE Annual Conference and Exposition, Conference Proceedings, 2018, vol. 2018-June.

[8] A. R. Van Dyke and J. Smith-Carpenter, "Bring Your Own Device: A Digital Notebook for Undergraduate Biochemistry Laboratory Using a Free, Cross-Platform Application," Journal of Chemical Education, vol. 94, no. 5, pp. 656-661, 2017, doi: 10.1021/acs.jchemed.6b00622.

[9] K. C. Bergsman, "The 'Structured' engineering design notebook: A new tool for design thinking within a studio design course," in ASEE Annual Conference and Exposition, Conference Proceedings, 2018, vol. 2018June.

[10] C. Walthall, C. Sauter, T. Deigendesch, S. Devanathan, A. Albers, and K. Ramani, "Survey of wikis as a design support tool," in DS 58-6: Proceedings of ICED 09, the 17th International Conference on Engineering Design, 2009, vol. 6, pp. 211-222.

[11] R. O. Buchal, "Collaborative Digital Design Notebooks," Proceedings of the Canadian Engineering Education Association (CEEA), 2017, doi: 10.24908/pceea.v0i0.10362.

[12] R. Buchal and E. Songsore, "Using Microsoft Teams to Support Collaborative Knowledge Building in the Context of Sustainability Assessment," Proceedings of the Canadian Engineering Education Association (CEEA), Nov. 2019, doi: 10.24908/pceea.vi0.13882.

[13] S. Ekwaro-Osire and P. O. Orono, "Design notebooks as indicators of student participation in team activities," in Proceedings - Frontiers in Education Conference, FIE, 2007, p. S2D18-S2D23, doi: 10.1109/FIE.2007.4418149.

[14] P. A. Brady and J. H. Rushing, "Using engineering design notebooks to evaluate student understanding of physics concepts in a design challenge," in ASEE Annual Conference and Exposition, Conference Proceedings, 2016, vol. 2016-June. 